\title{
Advanced Multi-laser-beam Parallel Heating System for Rapid High Temperature Treatment
}

\author{
XU Xiaoke ${ }^{1}$, DENG Mingxue ${ }^{1,2}$, LIU Qian ${ }^{1,2}$, YU Jianding ${ }^{1,2}$, ZHOU Zhenzhen ${ }^{1}$, ZHANG Xiang ${ }^{1,2}$, HE Huan ${ }^{1}$ \\ (1. State Key Laboratory of High Performance Ceramics and Superfine Microstructure, Shanghai Institute of Ceramics, Chinese \\ Academy of Sciences, Shanghai 200050, China; 2. Center of Materials Science and Optoelectronics Engineering, University of \\ Chinese Academy of Sciences, Beijing 100049, China)
}

\begin{abstract}
Rapid and high-throughput experimental methods are of great significance to the development of material genetic engineering technology. High temperature heat treatment is a necessary part for the preparation of inorganic non-metallic materials, while the rapid heat treatment technology of materials library needed for material genetic engineering is still blank. Here we report the multi-laser-beam parallel heating system which can be used in rapid high temperature treatment for samples arranged in an array of $\{A \times B\}$, named as materials library. We introduce the design principle, operation mode, structure details, and software of the multi-laser-beam parallel heating system. The facility presents many advantages of independent adjustment of laser heating time, power and spot size for each beam and high automation. The maximum laser power is above $100 \mathrm{~W}$, and the maximum stable heating temperature is $\sim 2000{ }^{\circ} \mathrm{C}$ for each laser beam. As a typical application demonstration, a series of sintering experiments of $\mathrm{Y}_{3} \mathrm{Al}_{5} \mathrm{O}_{12}: \mathrm{Ce}(\mathrm{YAG}: \mathrm{Ce})$ luminescent ceramics were carried out. Their heating temperature was $1400{ }^{\circ} \mathrm{C}, 1500{ }^{\circ} \mathrm{C}$ and $1600{ }^{\circ} \mathrm{C}$, while their holding time was 180, 360 and 540 s, respectively. Above facility operated automatically according to the pre-set heating positions and heating curves. All results show that, using the multi-laser-beam parallel heating system, fully-sintered samples with good crystallinity and luminescence properties can be obtained within several minute heat treatment, while the conventional sintering technology needs more than $10 \mathrm{~h}$. This study may provide a new technical solution for processing condition screening and high-throughput preparation of multi-samples in an energy and time saving mode.
\end{abstract}

Key words: multi laser beam; rapid parallel heating; sample array; independent control; YAG:Ce

It has been more than ten years since the Materials Genome Initiative (MGI) was proposed. Thanks to the efforts of universal researchers, innovative technologies the MGI needed, including high throughput computing, high throughput experiments, and specified materials database, have been developed ${ }^{[1-5]}$. As a key component of MGI, high throughput experiments can afford lots of raw data on materials properties. They can quickly obtain sample composition screening/performance optimization data, achieve the goal of halving research and development time and cost, and provide experimental database for material informatics and artificial intelligence mining of new materials. In the preparation of materials sample library, the multi-channel parallel synthesis of arrayed sample library is an important branch, which can realize the rapid preparation of multi samples. The spatial scale and volume of each independent sample in the sample array can meet the requirements of the existing structural characterization and performance testing technology. Thus, the correlation law between material composition, process, structure and performance can be established ${ }^{[6-8]}$.

High temperature heat treatment is a necessary part of material preparation, especially for inorganic nonmetallic materials such as metal and ceramics, which can realize chemical reaction, crystallization, densification and melting. However, the rapid heat treatment technology of materials library needed for material genetic engineering is still blank. Laser heating, attributed to its directionality and

Received date: 2021-03-21; Revised date: 2021-05-03; Published online: 2021-06-10

Foundation item: National Key Research and Development Program of China (2016YFB0700204, 2018YFB0704103)

Biography: XU Xiaoke(1984-), male, assistant professor. E-mail: xuxiaoke@mail.sic.ac.cn

徐小科(1984-), 男, 助理研究员. E-mail: xuxiaoke@mail.sic.ac.cn

Corresponding author: LIU Qian, professor. E-mail: qianliu@mail.sic.ac.cn

刘 茜, 研究员. E-mail: qianliu@mail.sic.ac.cn 
high energy density, should be one of the most effective heating technologies for materials library ${ }^{[9-10]}$.

Nevertheless, some of the laser heating technologies that have been developed are suitable for single beam laser point-to-point heating of thin film samples ${ }^{[11-13]}$, multi beam laser low-temperature thermal etching to prepare micro phase difference films ${ }^{[14]}$, or laser welding and detection of solder joint over burning ${ }^{[15-16]}$. Obviously, these technologies are not suitable for the rapid high temperature heat treatment of series sample library. Therefore, it is necessary to develop parallel rapid high temperature heat treatment technology and equipment for the arrayed sample library to meet the urgent needs of rapid experimental technology for MGI, that is exactly what we have done in research and development of the multi-laser-beam parallel heating system.

\section{Multi-laser-beam parallel heating system}

In our design, the multi-laser-beam parallel heating system possesses following functions: (1) Laser beams with different power and spot size can heat samples at different positions in an array $\{\mathrm{A} \times \mathrm{B}\}$ at the same time. (2) The spot size, power and heating time of different laser beams can be adjusted independently. (3) The laser heating process can be programmed and automated. (4) Sample array or materials library can move along $X-Y$ direction to match with laser beam position.

Fig. 1 shows the schematic diagram of a typical threechannel laser heating system. The facility mainly constructs: (1) 3 laser sources and optical components including 3 beam expanders which can change the laser beams to required spot size $(2-6 \mathrm{~mm})$ and 3 reflectors $\left(45^{\circ}\right)$ which can make laser beam be directed to heat the

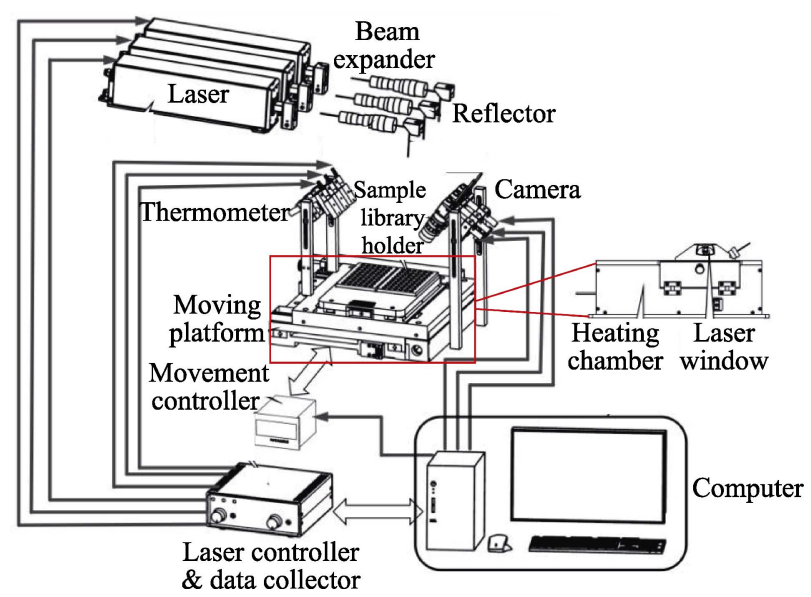

Fig. 1 Schematic diagram of a typical three-laser-beam parallel heating system, mainly including laser sources, reflectors, sample library holder and moving platform, computer, and controllers samples below; (2) A chamber in which there are sample library holder and $X-Y$ moving platform, and protective atmospheres can pass into in case of sample oxidation; (3) 3 thermometers and 3 infrared cameras for getting real time-temperature and heating images, respectively.

(4) Computer and other controllers.

When the facility works, firstly powder or plate samples are placed in the sample library holder, and the moving platform would take the sample library holder to the designated position. Then the laser sources are turned on, and after passing through the beam expanders, the reflectors and the laser windows on the top of the chamber, the laser beams irradiate on the surface of samples to heat them. Meanwhile, the thermometers and infrared cameras gather the real time-temperature and heating images of samples to the computer. When the heating of a group of 3 samples in the array are completed, the moving platform would take the sample library holder to a new position and the heating process is repeated until all samples in the array are heated.

Fig. 2 shows the vivid photograph of the self-built three-laser-beam parallel heating system. As shown in Fig. 2, the system can be regarded as three parts on the whole. In the upper part, three laser sources and corresponding beam expanders and reflectors are arranged neatly. The laser source is continuous and its wavelength is $10.6 \mu \mathrm{m}$, while the maximum power of each laser is about $100 \mathrm{~W}$. The laser beam diameter can be enlarged to 2-6 times by the beam expanders, and the reflectors installed at $45^{\circ}$ can change the laser beam from horizontal to vertical. The middle part, shown in Fig. 2(c), contains the heating chamber, thermometers and infrared cameras. The thermometers are infrared sensitive and contactless,

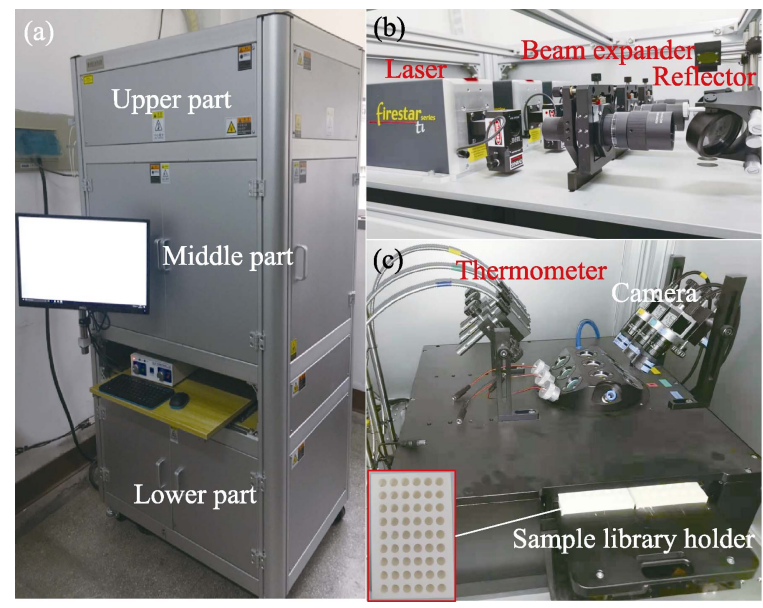

Fig. 2 Photograph of various parts in the typical three-laserbeam parallel heating system

(a) Overall appearance; (b) Upper part, including 3 laser sources, 3 beam expanders and 3 reflectors; (c) Middle part, mainly containing 3 thermometers, 3 infrared cameras, 1 chamber and 1 sample library holder/moving platform 
while the measurement range is $500-3000{ }^{\circ} \mathrm{C}$. On the top of the chamber, there are windows corresponding to laser beams, thermometers and cameras respectively. The sample library holder, shown in the inset of Fig. 2(c), is made of alumina ceramics. The holes are evenly distributed in the sample library holder, forming a $\{6 \times 9\}$ array, which can be used to hold the samples to be heated. The moving platform is mainly composed of $X-Y$ direction stepping motor tracks, which can move the sample library holder to the designated position. The lower part contains computer, laser controller and motor controller, which compose the control center of the system.

The working of the multi-laser-beam parallel heating platform is supported by the Heating-Platform software. Fig. 3(a) shows the main window of the HeatingPlatform software. In the left part of the main window, there are 54 small squares arranged in a $\{6 \times 9\}$ array. The nine rows in the array are numbered from a to $i$, and the six columns are numbered from 1 to 6 . In this way, the small squares in the array can be numbered from a1 to i6, which indicates a sample position on the sample library holder. In the right part, there are six charts with three rows and two columns, which are used to show the real time-temperature curves and heating images for recording the laser beam parallel heating. In the system the heating parameters (laser power-dominated temperature and thermometer-feedback time for each position) can be set independently, which can be realized by the designed programming in Heating-Platform software. When any one of the 54 square areas in the main window of the Heating-Platform software is clicked, a pop-up window for programming appears as shown in Fig. 3(b). There

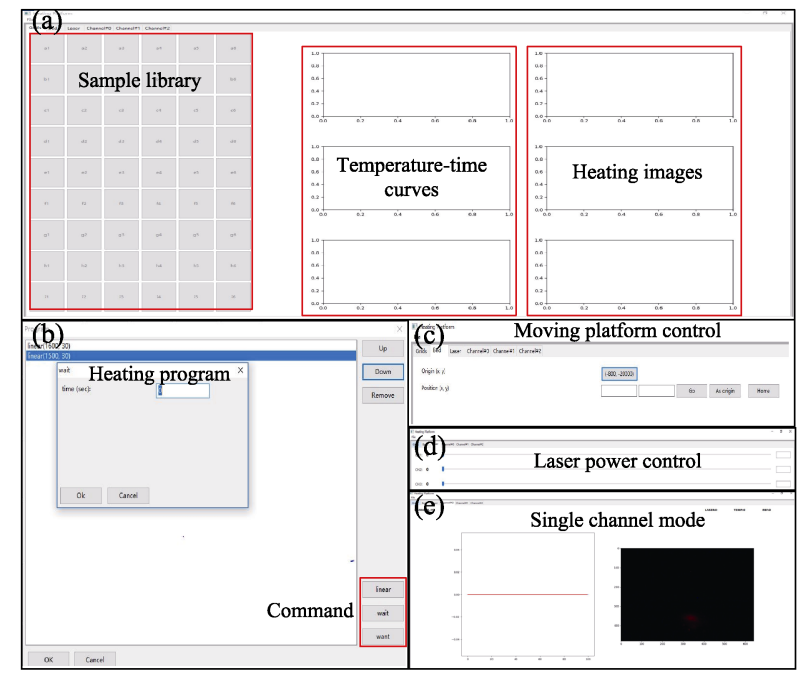

Fig. 3 Software interface of the multi-laser-beam parallel heating system

(a) Main window; (b) Programming window; (c) Moving platform control; (d) Laser power control; (e) Single channel (one-laser-beam) mode are three programming commands for the heating process, "linear", "wait", and "want". The "linear (temperature, time)" command means the sample will be heated to the specified temperature in the specified time linearly. The "wait (time)" command will perform a temperature holding action for the specified time. When the "want (temperature)" command is used, it means the highest heating rate to the specified temperature, regardless of whether the heating process is linear or not. There are other windows in the Heating-Platform software, shown in Figs. 3(c-e), which can be used to perform the manual adjustment of the moving platform and laser power, and the view of temperature curve and heating image in single channel (one-laser-beam) mode, respectively.

\section{Application in rapid high tempera- ture treatment of YAG:Ce}

$\mathrm{Ce}^{3+}$ doped yttrium aluminum garnet (YAG:Ce ${ }^{3+}$ ) phosphor is widely used in white LED lighting because of its stable physical characteristics, high luminous efficiency and wide emission spectrum. Conventional method for YAG: $\mathrm{Ce}^{3+}$ preparation is solid state sintering, and it costs more than $10 \mathrm{~h}^{[17-19]}$. As a typical application, we carried out the YAG: $\mathrm{Ce}^{3+}$ ceramic preparation experiments using a three-laser-beam parallel heating system, and the prepared samples were characterized by XRD phase analysis and photoluminescence spectrum.

Experiments: After grinding the mixed powders of ceria, alumina and yttrium oxide according to the stoichiometric ratio of $\mathrm{Y}_{3-x} \mathrm{Al}_{5} \mathrm{O}_{12}: x \mathrm{Ce}(x=0.03)$, the powder plates with thickness of $2 \mathrm{~mm}$ and diameter of $5 \mathrm{~mm}$ were pressed with pressure of $6 \mathrm{MPa}$. Then the plates were pre-sintered at $800{ }^{\circ} \mathrm{C}$ in muffle furnace at a heating rate of $4{ }^{\circ} \mathrm{C} / \mathrm{min}$ for removal of binder. The pre-sintered samples were placed in the corresponding positions of a $\{3 \times 3\}$ array sample holder, and then the laser heating experiments were carried out. The heating time was fixed at $30 \mathrm{~s}$, and the target temperature was 1400, 1500, $1600{ }^{\circ} \mathrm{C}$, respectively. For each target temperature, there were three holding time, 180, 360 and $540 \mathrm{~s}$.

Fig. 4(a) shows the screenshot of the Heating-Platform software during a three-laser-beam parallel heating process. One group of 3 red squares indicating the corresponding positions of 3 samples of YAC:Ce plates located on were being heated at the same time, setting the heating parameters to $1400{ }^{\circ} \mathrm{C}$ for 180,360 and $540 \mathrm{~s}$. Then, the second group (3 yellow squares) of three samples were moved to the heating positions for the extended heating temperature of $1500{ }^{\circ} \mathrm{C}$ for 180,360 

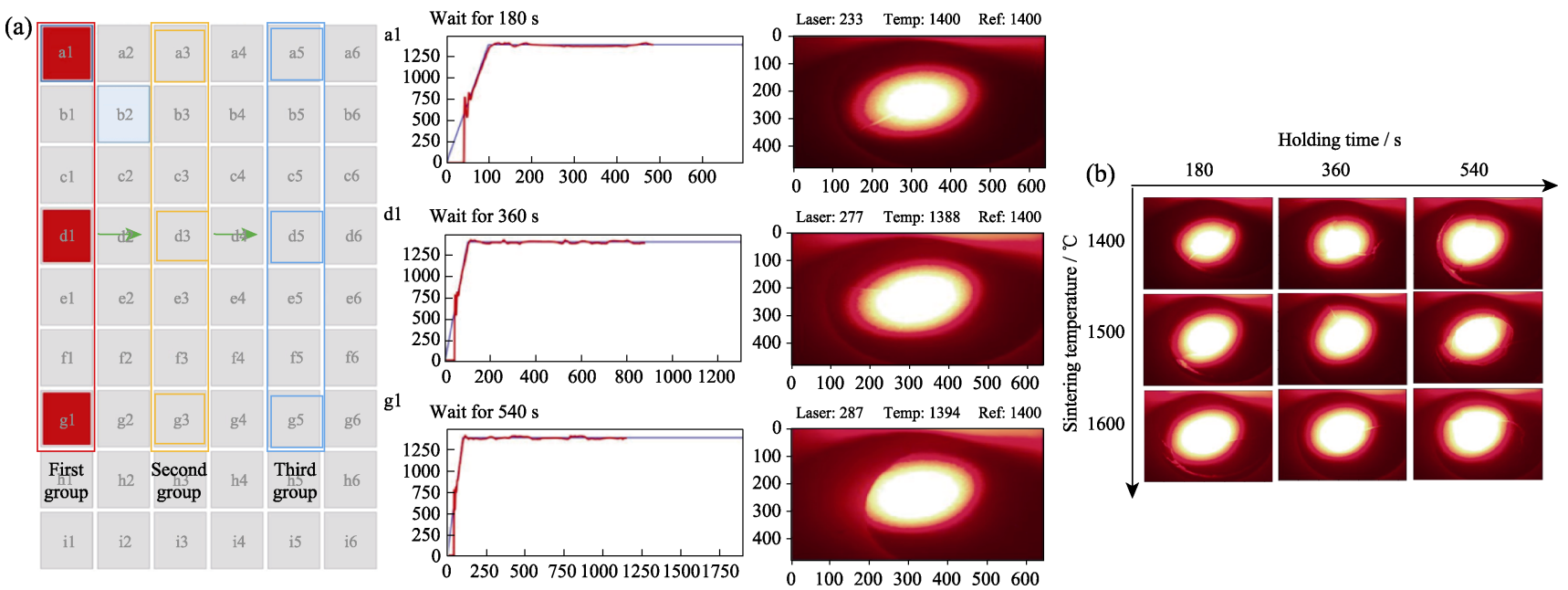

Fig. 4 (a) Screenshot of the Heating-Platform software during three-laser-beam parallel heating process with heating curves and heating spots, and (b) real time observation images of heating spots during laser heating with increasing of temperature and holding time

and 540 s. Finally, the third group ( 3 blue squares) of three samples experienced the maximum heating temperature of $1600{ }^{\circ} \mathrm{C}$ for 180,360 and $540 \mathrm{~s}$. Thus a $\{3 \times 3\}$ array of YAG:Ce ceramic samples were laserheated under varied temperatures (1400-1600 $\left.{ }^{\circ} \mathrm{C}\right)$ and holding time (180-540 s). From the temperature-time curves, we can see that the real-time curves (red curve) are in good agreement with the preset curves (black curve) in addition to the rapid temperature increasing of laser heating in the initial stage, which demonstrates the powerful and precisely controlled synchronous heating capability of the laser heating system in temperature control. Some other information can be also got such as laser power, real-time temperature, reference temperature and holding time. What deserves special attention is that the laser power and holding time of the three laser beams are different in the three groups of samples heating, which indicates that the laser power and heating time of the three laser beams can be adjusted independently. Fig. 4 (b) shows the real-time image of the $\{3 \times 3\}$ array of YAG:Ce ceramic sample during the laser heating process. It can be seen that the laser heating areas are all in the center of the sample, and the size of the heating areas is nearly the same, and the shape is about oval.

The laser heated 9 samples were all characterized by XRD to identify the crystal phase. As shown in Fig. 5, all samples show the mixture phase of dominated host $\mathrm{Y}_{3} \mathrm{Al}_{5} \mathrm{O}_{12}$ (PDF\#33-0040) and a small amount of unreacted $\mathrm{Al}_{2} \mathrm{O}_{3}$ (PDF\#10-1173), and with the increase of heating temperature and holding time, $\mathrm{Y}_{3} \mathrm{Al}_{5} \mathrm{O}_{12}$ phase gradually dominates. In the XRD pattern of the sample heated at $1500{ }^{\circ} \mathrm{C}$ for $540 \mathrm{~s}$, the polycrystalline background is smaller, which implies that the heating condition of $1500{ }^{\circ} \mathrm{C}$ for $540 \mathrm{~s}$ can be considered as an optimized one to obtain a well-crystallized phase with few impurities. The inset shows the XRD patterns of solid-state sintering Ce-doped $\mathrm{Y}_{3} \mathrm{Al}_{5} \mathrm{O}_{12}$ nanopowders ${ }^{[20]}$. It can be seen from the comparison that the XRD diffraction peak positions of the samples obtained by the two different experimental methods are consistent.

Fig. 6 shows the emission spectra (PL) of the laserheated samples excited by $450 \mathrm{~nm}$ blue light. It can be seen from the figure that the emission peaks of all samples show a broad peak centered at $570 \mathrm{~nm}$ from the
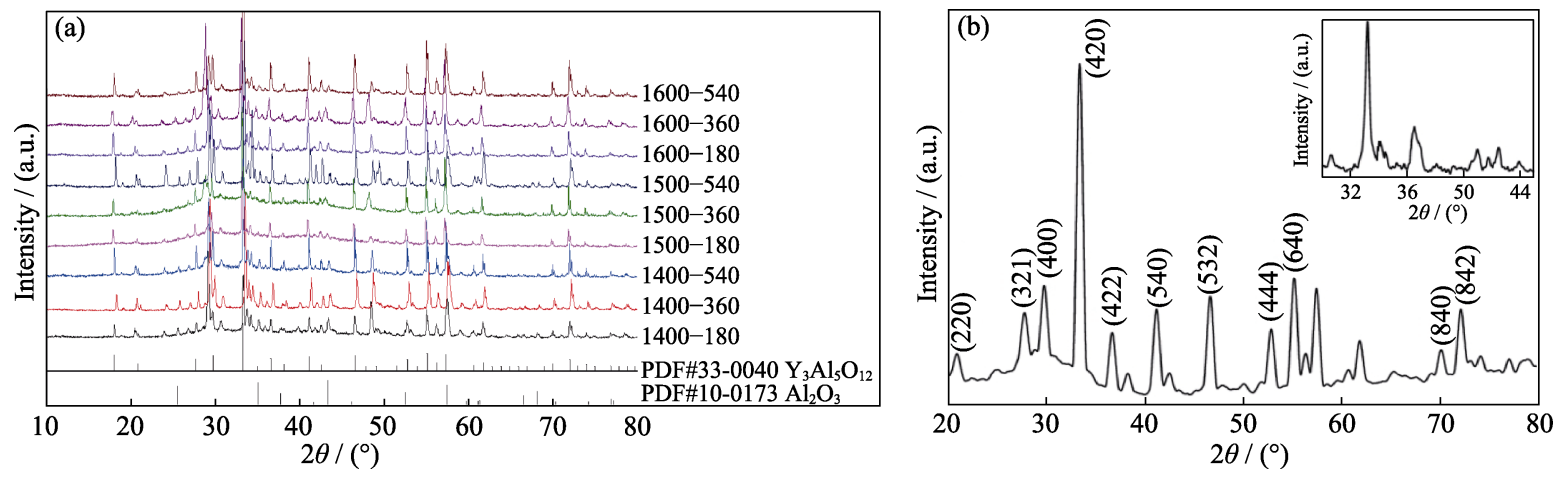

Fig. 5 (a) XRD patterns of the YAG:Ce samples after laser heating with different temperatures and holding time, and (b) XRD patterns of solid-state sintering Ce-doped $\mathrm{Y}_{3} \mathrm{Al}_{5} \mathrm{O}_{12}$ nanopowders for comparison ${ }^{[20]}$ 


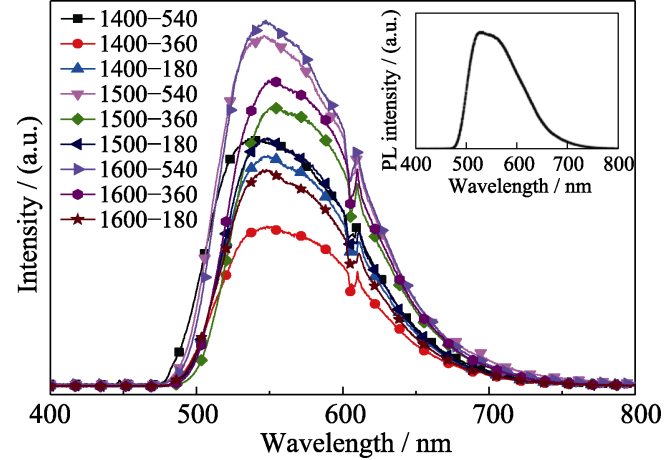

Fig. 6 PL spectra of the YAG:Ce ceramic samples after laser heating under varied conditions with the exciting wavelength at $450 \mathrm{~nm}$

Inset: PL spectra of solid-state sintering Ce-doped $\mathrm{Y}_{3} \mathrm{Al}_{5} \mathrm{O}_{12}$ nanopowders at $442 \mathrm{~nm}$ excitation wavelength ${ }^{[20]}$

typical $5 \mathrm{~d}-4 \mathrm{f}$ transition of $\mathrm{Ce}^{3+}$, which is also consistent with the emission spectrum of YAG:Ce ceramics obtained by conventional solid-state sintering method. In addition, under the same test conditions, the higher the laser sintering temperature and the longer the holding time, the higher the intensity of emission spectrum of samples is, which is also consistent with the proportion of $\mathrm{Y}_{3} \mathrm{Al}_{5} \mathrm{O}_{12}$ dominant phase in XRD test. The inset shows the PL spectra of solid-state sintering Ce-doped $\mathrm{Y}_{3} \mathrm{Al}_{5} \mathrm{O}_{12}$ nanopowders at $442 \mathrm{~nm}$ excitation wavelength ${ }^{[20]}$. The peak shapes of the emission spectrum of samples obtained by the two different experimental methods are exactly the same, and the peak positions are slightly shifted, which may be caused by the different excitation wavelengths and samples form. On the whole, after a few minutes of laser sintering, the crystal phase and spectral property of the YAG:Ce ceramics samples are very close to those by the conventional solid-state sintering method, which usually takes more than $10 \mathrm{~h}$ of sintering at higher temperature above $1700{ }^{\circ} \mathrm{C}$.

\section{Conclusions}

The multi-laser-beam parallel heating system has been designed and built for realizing rapid high temperature sintering of sample library or sample array. The system uses mid-infrared continuous laser of $10.6 \mu \mathrm{m}$ to irradiate the inorganic nonmetallic samples surface for high-energy directional heating after beam expansion and reflection, with independently adjustable temperature and time of heating. By using non-contact infrared temperature measurement and real-time monitoring technology, the whole process of laser sintering is safe, efficient and automatic. Typical YAG:Ce luminescent ceramic sintering experiments show that the crystal phase and emission spectral property of the samples obtained by rapid laser sintering under optimal conditions of $1500{ }^{\circ} \mathrm{C}$ for $540 \mathrm{~s}$ are very close to those obtained by conventional timeconsuming solid sintering at much higher temperatures for more than $10 \mathrm{~h}$. The research also shows that the multilaser-beam parallel heating system presents a good application prospect in the field of rapid high temperature sintering, especially for the screening of sintering conditions and high-throughput preparation of multi samples.

\section{References:}

[1] XU Y F, ELCORO L, SONG Z D, et al. High-throughput calculations of magnetic topological materials. Nature, 2020, 586(7831): 702-707.

[2] SHEN Z H, WANG J J, LIN Y H, et al. High-throughput phase-field design of high-energy-density polymer nanocomposites. Advanced Materials, 2018, 30(2): 1704380-1-6.

[3] GAN L T, YANG R, TRAYLOR R, et al. High-throughput growth of microscale gold bicrystals for single-grain-boundary studies. Advanced Materials, 2019, 31(32): 1902189-1-7.

[4] SEOL M, LEE M H, KIM H, et al. High-throughput growth of wafer-scale monolayer transition metal dichalcogenide via vertical ostwald ripening. Advanced Materials, 2020, 32(42): 2003542-1-8.

[5] JIANG J K, SHEA G, RASTOGI P, et al. Continuous highthroughput fabrication of architected micromaterials via in-air photopolymerization. Advanced Materials, 2021, 33(3): 2006336-1-9.

[6] LI J H, DU P P, LI S R, et al. High-throughput combinatorial optimizations of perovskite light-emitting diodes based on all-vacuum deposition. Advanced Functional Materials, 2019, 29(51): 1903607-1-8.

[7] ZHANG Z M, LINDLEY S A, GUEVARRA D, et al. Fermi level engineering of passivation and electron transport materials for p-type $\mathrm{CuBi}_{2} \mathrm{O}_{4}$ employing a high-throughput methodology. Advanced Functional Materials, 2020, 30(24): 2000948-1-12.

[8] LIN B H, HEDRICK J L, PARK N H, et al. Programmable high-throughput platform for the rapid and scalable synthesis of polyester and polycarbonate libraries. Journal of the American Chemical Society, 2019, 141(22): 8921-8927.

[9] DAHL J C, WANG X Z, HUANG X, et al. Elucidating the weakly reversible $\mathrm{Cs}-\mathrm{Pb}-\mathrm{Br}$ perovskite nanocrystal reaction network with high-throughput maps and transformations. Journal of the American Chemical Society, 2020, 142(27): 11915-11926.

[10] WANG H Y, JING Z, LIU H L, et al. A high-throughput assessment of the adsorption capacity and Li-ion diffusion dynamics in Mo-based ordered double-transition-metal MXenes as anode materials for fast-charging LIBs. Nanoscale, 2020, 12(48): 24510-24526.

[11] MENG Q B, ZHOU X L, LI J H, et al. High-throughput laser fabrication of Ti-6Al-4V alloy: Part I. Numerical investigation of dynamic behavior in molten Pool. Journal of Manufacturing Processes, 2020, 59: 509-522.

[12] REN Y M, ZHANG Y C, DING Y Y, et al. Computational fluid dynamics-based in-situ sensor analytics of direct metal laser solidification process using machine learning. Computers \& Chemical Engineering, 2020, 143: 107069-1-14.

[13] HOLDER D, WEBER R, ROCKER C, et al. High-quality high-throughput silicon laser milling using a $1 \mathrm{~kW}$ sub-picosecond laser. Optics Letters, 2021, 46(2): 384-387. 
[14] SHIN S, HUR J G, PARK J K, et al. Thermal damage free material processing using femtosecond laser pulses for fabricating fine metal masks: influences of laser fluence and pulse repetition rate on processing quality. Optics and Laser Technology, 2021, 134: 106618-1-8.

[15] GONG X Y, YABANSU Y C, COLLINS P C, et al. Evaluation of Ti-Mn alloys for additive manufacturing using high-throughput experimental assays and Gaussian process regression. Materials, 2020, 20(13): 4641-1-19.

[16] MINCUZZI G, REBIERE A, FAUCON M, et al. Beam engineering strategies for high throughput, precise, micro-cutting by $100 \mathrm{~W}$, femtosecond lasers. Journal of Laser Applications, 2020, 32(4): 042003-1-8.

[17] HUH D, KIM W, KIM K, et al. Enhancing light conversion efficiency of YAG:Ce phosphor substrate using nanoimprinted functional structures. Nanotechnology, 2020, 31(14): 144003-1-5.

[18] XU YW, CHEN J, ZHANG H, et al. White-light-emitting flexible display devices based on double network hydrogels crosslinked by YAG:Ce phosphors. Journal of Materials Chemistry C, 2020, 8(1): $247-252$.

[19] TUCUREANU V, ROMANITAN C, TUDOR I A, et al. Effect of process parameters on YAG:Ce phosphor properties obtained by co-precipitation method. Ceramics International, 2020, 46(15): 23802-23812.

[20] CHUNG D N, HIEU D N, THAO T T, et al. Synthesis and characterization of Ce-doped $\mathrm{Y}_{3} \mathrm{Al}_{5} \mathrm{O}_{12}$ (YAG:Ce) nanopowders used for solid-state lighting. Journal of Nanomaterials, 2014, 2014: 571920-1-7.

\section{可用于快速高温热处理的多束激光并行加热系统}

徐小科 ${ }^{1}$, 邓明雪 ${ }^{1,2}$, 刘 茜 $^{1,2}$, 余建定 ${ }^{1,2}$, 周真真 ${ }^{1}$, 张 翔 $^{1,2}$, 贺 欢 ${ }^{1}$ (1. 中国科学院 上海硅酸盐研究所, 高性能陶瓷和超微结构国家重点实验室, 上海 $200050 ; 2$. 中国科学院大学 材料科学与光电研究工程中心, 北京 100049)

摘 要: 快速、高通量的实验方法对材料基因工程技术的发展具有重要意义。高温热处理对无机非金属材料的制备 往往是必不可少的环节, 然而针对材料基因工程所需的材料样品库快速热处理技术目前尚是空白。本文报道了一种 可用于快速高温热处理阵列样品的多束激光并行加热系统, 介绍了多束激光并行加热系统的设计原理、工作方式、 结构细节和软件设计。该装置具有激光加热时间、功率、光斑大小可独立调节、自动化程度高等优点, 最大单束激 光功率大于 $100 \mathrm{~W}$, 每束激光的最大稳定加热温度约为 $2000{ }^{\circ} \mathrm{C}$ 。作为典型的应用示范, 进行了一系列 $\mathrm{Ce}^{3+}$ 掺杂钎 铝石榴石发光陶瓷的烧结实验, 加热温度分别为 $1400 、 1500$ 和 $1600{ }^{\circ} \mathrm{C}$ ，保温时间分别为 $180 、 360$ 和 $540 \mathrm{~s}$, 仪器按 照设置好的加热位置和加热曲线自动运行。结果表明: 采用多束激光并行加热系统, 可以在几分钟的热处理时间内 获得结晶度和发光性能良好的烧结样品, 比传统制备工艺十余小时的烧结时间大幅缩短。这将为高温热处理的条件 篮选和高通量制备提供一种节能省时的新技术方案。

关 键 词: 多束激光; 快速并行加热; 阵列样品; 独立控制; YAG:Ce

中图分类号: TQ174 文献标志码: A 